\title{
Intervenção Psicológica em uma Unidade de Transplante Renal de um Hospital Universitário
}

\author{
Psychological assistance of the renal transplantation \\ departament at a university hospital
}

Maria Lúcia

Pinheiro Garcia,

Universidade Estadual do Ceará

Ângela Maria

Alves e Souza

Universidade Federal do Ceará

Teresa Cristina Holanda

Hospital Universitário Walter

Cantídio, da Universidade

Federal do Ceará 
Resumo: Este artigo relata um caso acompanhado no ambulatório de pré-transplante e na unidade de transplante renal de um hospital universitário, pela psicóloga vinculada ao projeto de Extensão de Capacitação em Psicologia Hospitalar pela Universidade Federal do Ceará. Utilizamos, como suporte teórico, a abordagem sistêmica e a técnica de psicoterapia breve, focalizando doença, internação e alta. Observamos que o processo de receber e de doar, no transplante renal, perpassa pela dinâmica individual do doador, do receptor e da família, ativando conflitos inconscientes que influenciam na decisão e no equilíbrio emocional do paciente.

Palavras-chave: transplante renal, assistência psicológica, apoio, psicoterapia breve.

\begin{abstract}
This present paper is a case report from the pre-transplantation out-patient service of the renal transplantation department at a university hospital in Northeastern Brazil, followed by a psychologist, as part of a training program in Hospital Psychology by the Federal University of Ceará. The theoretical framework included systemic approach and brief psychotherapy and was focused on disease, hospitalization and discharge. In renal transplantation, it was observed that the process of donating and receiving involved the individual dynamics of donor, recipient and family, activating unconscious conflicts capable of affecting the patient's decision-making ability and emotional balance.
\end{abstract}

Key words: renal transplantation, psychological assistance, support, brief psychotherapy.

Em janeiro de 2000, a primeira autora foi selecionada para atuar como extensionista no Projeto de Extensão de Capacitação em Psicologia Hospitalar pela Universidade Federal do Ceará, supervisionado pela psicóloga chefe (terceira autora) do Serviço de Psicologia do Hospital Universitário Walter Cantídio (HUWC). O Projeto de Extensão de Capacitação Hospitalar tinha como objetivo desenvolver o Programa de Assistência Psicológica (PAP) na Unidade de Transplante Renal. O PAP visava ao atendimento às pessoas com deficiência renal em qualquer estádio do tratamento - na avaliação e acompanhamento psicológico para dar início aos exames pré-transplante ou na enfermaria, por qualquer tipo de intercorrência pré e/ou pós-transplante.

Neste estudo, faremos algumas considerações sobre o papel do psicólogo na instituição hospitalar e apresentaremos a abordagem teórica, os recursos técnicos utilizados e a descrição das atividades desenvolvidas na
Unidade de Transplante Renal do Hospital Universitário. Em seguida, discorreremos sobre um estudo de caso com o objetivo de mostrar os diferentes focos das intervenções psicológicas realizadas durante o acompanhamento, que respondeu aos diferentes momentos existenciais surgidos no ambulatório de pré-transplante, na enfermaria e no ambulatório de pós-transplante, no total de quinze atendimentos, correspondente à duração do processo de transplante, ou seja, da primeira consulta médica à alta, de junho a dezembro de 2000. O tempo cronológico, portanto, correspondeu às exigências institucionais, um dos fatores importantes a ser considerado para a atuação do psicólogo em um hospital, o que, no entanto, não o impossibilita de realizar um trabalho satisfatório. Selecionamos oito atendimentos que ilustram o contexto psicológico pelos quais passaram o doador, o receptor e a família, inseridos na sua realidade social. 
A escolha desse caso correspondeu ao interesse da psicóloga, primeira autora, em investigar a dimensão relacional familiar no contexto de transplante com doador vivo.

\section{O psicólogo na instituição hospitalar}

Segundo Angerami (1997), quando estamos inseridos no âmbito hospitalar, estamos diretamente determinados por limites institucionais, pela instituição em si - o hospital-, caracterizado por normas, rotinas, condutas específicas, dinâmicas que devem ser respeitadas e seguidas, limitando as nossas possibilidades de atuação.

No HUWC, interagimos com a equipe de saúde, adequando nossas ações e estabelecendo fluxos de comunicação, em virtude da necessidade de dar múltiplos enfoques para o mesmo problema, pois, além da demanda vir de várias direções - do paciente, da família, da equipe -, a delimitação do tempo interfere diretamente na prática do psicólogo pela grande rotatividade dos leitos, pela gravidade da doença, dentre outras. No caso de atendimento na enfermaria, utilizamos técnicas que possibilitaram o atendimento emergencial e focal, e, no caso de atendimento ambulatorial, tentamos marcar o retorno para acompanhamento psicológico, associado ao retorno médico porque, em algumas intervenções de esclarecimento, é necessária a sua presença, além de levar também em consideração as dificuldades financeiras e a localização residencial do paciente. Observamos, também, o tempo (seis meses) de que o paciente dispunha para os exames físicos e psicológicos para dar entrada na fila de doação de rim.

O ambulatório de pré-transplante do HUWC segue uma rotina iniciada pelo acompanhamento do médico, da enfermeira e da psicóloga. Esse atendimento multiprofissional se mostrou vantajoso, principalmente durante a primeira consulta, pois a quantidade de informações e esclarecimentos realizados tanto pelo médico como pela enfermeira ocasionava uma mobilização emocional em que o paciente tinha a oportunidade de integrar mencionadas informações ao atendimento psicológico. Quando, após a avaliação psicológica, o acompanhamento se fazia necessário, este era realizado nesse mesmo local.

Antes da primeira entrevista psicológica, o paciente tem um contato com a enfermeira que lhe dá as orientações quanto aos exames a serem realizados e quanto ao transplante duração, procedimento, anestesia, possíveis complicações -, além de particularizar a necessidade e o objetivo dos exames indicados. Também discorre sobre a importância das consultas pós-transplante e as vantagens e desvantagens do transplante e limitações na vida do transplantado.

O preparo psicológico para o transplante é necessário porque as reações são as mais diversas possíveis e dependem da significação que o paciente dá ao órgão substituído, suas experiências, preparo para adaptar-se às novas condições de vida, ao conhecimento real ou fantasioso do que está acontecendo, dentre outras variáveis.

Lidamos com um paciente que apresenta sofrimento psíquico sobreposto ao sofrimento físico. É necessário entendê-lo na sua totalidade, num contexto de mal-estar, de seqüelas do tratamento, de hospitalização (Chiattone, 2000). No HUWC, levamos em consideração o momento do indivíduo e todas as características da situação especial e crítica da deficiência, do transplante, hospitalização e reabilitação: é a esse momento de crise na história da pessoa que nos atemos. No atendimento hospitalar, o paciente não faz uma escolha para ser atendido como acontece quando do tratamento clínico tradicional, uma vez que é a equipe de saúde que faz a indicação. Precisamos estar atentos ao manuseio 
das intervenções para que, à condição do paciente, não sejam acrescentados medos e ansiedades.

Os recursos teóricos utilizados podem ser determinantes para a condução do processo terapêutico, visto ter o contexto hospitalar suas peculiaridades. O psicólogo hospitalar se diferencia muito do psicólogo clínico, porque atuar nesse contexto é estar atento a todas as relações que o paciente desenvolve com a equipe multiprofissional, com ele mesmo e com a família, dentro de uma fragilidade física. É nessa teia relacional que as intervenções são realizadas e acontecem em um espaço de tempo muito breve, enquanto o paciente está no contexto hospitalar.

\section{Recursos utilizados para as intervenções - abordagem sistêmica familiar, teoria de crise e técnica de psicoterapia breve de apoio}

Para a leitura e o manejo dos conflitos que emergiram nesse caso, foi buscado apoio na literatura, por intermédio dos autores Minuchin (1982), Papp (1992) e Satir (1988), que desvelam as relações na abordagem sistêmica familiar. Foram utilizadas, também, a teoria de crise de Caplan (1960) e a técnica de psicoterapia breve de apoio (PBA).

Para Papp (1992), “...o que é assinalado por teoria dos sistemas, em terapia familiar, é uma imprecisa série interligada de conceitos enraizados na teoria geral dos sistemas e na cibernética" (p. 22).

Os conceitos-chave do pensamento sistêmico têm estreita relação com a totalidade, a organização e a padronização. As idéias centrais dessa teoria são as de que o todo é considerado maior do que a soma de suas partes. Uma mudança em qualquer uma das partes altera as outras e o todo se regula para manter o sistema equilibrado. O conceito da padronização e organização circular indica que nenhum evento ou parte de um comportamento causa outro, e, sim, que cada um está ligado, de maneira circular, a muitos outros eventos e partes de comportamentos. Ao longo do tempo, os padrões constantes funcionam para equilibrar a família. O papel do terapeuta é identificar esses comportamentos, inclusive o sintoma e sua função dentro do sistema (Papp, 1992).

Satir (1988) enfatiza a importância da comunicação no comportamento interacional e postula a idéia de que a doença familiar é derivada de métodos inadequados de comunicação entre os membros da família. Os membros de famílias funcionais se manifestam com clareza, deixando aparecer abertamente o que pensam e sentem; tratam a presença das diferenças mais como oportunidades de aprender e crescer do que como ameaça ou sinal de conflito.

As famílias funcionais empregam efetivamente seus recursos para solucionar os problemas do grupo familiar; ao mesmo tempo, preocupamse com as necessidades emocionais de cada membro.

Para Minuchin (1982), a estrutura familiar é um conjunto invisível de exigências funcionais que organiza as maneiras pelas quais os membros da família interagem. A origem dessas expectativas está mergulhada em anos de negociação explícita e implícita entre os membros da família, freqüentemente, em torno de pequenos eventos do cotidiano. Assim, o sistema oferece resistência à mudança. Quando surgem situações de desequilíbrio no sistema, é comum que os membros da família façam reivindicações de lealdade familiar e manobras que induzem culpa. O que se espera de normalidade é que a família se adeque às mudanças internas e externas, adaptando-se às novas circunstâncias sem perder a continuidade.

Caplan (1960) define crise como um estado de perturbação, usualmente associado a sentimentos de desconforto, tais como
As famílias funcionais empregam efetivamente seus recursos para solucionar os problemas do grupo familiar; ao mesmo tempo, preocupam-se com as necessidades emocionais de cada membro. 
angústia, medo, culpa ou vergonha, que ocorre quando o indivíduo é exposto a um problema insuperável pelos seus meios habituais de solução, durante um certo tempo, e outros métodos não lhe parecem disponíveis.

A técnica de PBA, já definida para o desenvolvimento do Programa de Apoio Psicológico, é também um recurso utilizado na abordagem sistêmica familiar para operacionalizar o planejamento das sessões porque possibilita promover, no menor tempo possível, a elaboração de mudanças, conscientização de situações inconscientes e modificações de condutas dentro de pontos de urgência previamente selecionados no momento da entrevista admissional (Lemgruber, 1997). No contexto da assistência psicológica hospitalar no qual se inscreve este estudo, os pontos de urgência previamente selecionados foram a doença, a internação e o tratamento.

Gouvêa (2000) denomina psicoterapia breve de apoio uma forma de tratamento que utiliza medidas diretas para manter ou restabelecer o funcionamento anterior do paciente por meio da melhora ou supressão dos sintomas, e para manter, restaurar ou aumentar a autoestima, visando a um aumento do nível de funcionamento do paciente, levando-o a ter o controle de estratégias para lidar com suas dificuldades. O principal foco da PBA são as circunstâncias atuais de vida do paciente.

Para Chiatonne (2000), a psicoterapia de apoio também é indicada a pacientes que passam por sobrecarga emocional crônica, como processos orgânicos irreversíveis ou incuráveis. Em ambos os casos, a tarefa no hospital objetiva, fundamentalmente, auxiliá-lo a atravessar o período crítico em que se encontra, determinado pelo processo de doença e hospitalização, permitindo-lhe buscar a elaboração e integração subjetiva dos acontecimentos.
Algumas das principais intervenções empregadas na técnica da PBA são: sugestão, controle ativo, reasseguramento, aconselhamento, ventilação (desabafo), educação, clarificação, confrontação (Cordioli, 1993).

Os critérios para alta são: indicação de que o paciente diminuiu a ansiedade, melhorou os sintomas perturbadores, apresenta relativa compreensão interna das fontes de ansiedade e/ou de conflitos e mecanismos de defesa inadequados, aumento na capacidade de tolerar frustrações; aumento da capacidade de auto-observação, dentre outros.

\section{Descrição da intervenção psicológica na unidade de transplante renal - ambulatório de pré-transplante, enfermaria e ambulatório de pós- transplante}

O paciente renal crônico (PRC) tem seis meses para realizar exames físicos e psicológicos para dar entrada na lista de espera de doador de rim, quando sua escolha é aguardar um rim de cadáver. Na situação de doador vivo, a avaliação psicológica inclui o receptor e o doador do rim. O acompanhamento psicológico é realizado com todos os envolvidos no processo emocional: doador, receptor e família.

Na situação de doador-cadáver, este precisa ser de uma pessoa que estava em estado saudável até antes da morrer, de preferência jovem e com os órgãos em condições de doação.

O doador vivo ideal é aquele espontâneo, que não é alvo de pressão de nenhuma ordem. É importante levar isso em consideração, pois, muitas vezes, a doação é feita como forma de o doador expiar alguma culpa, sentir-se compensado por ajudar alguém ou como fuga para satisfazer a incapacidade de resolver seus problemas (Uryn, 1992). 
A entrevista psicológica com o doador tem o objetivo de investigar os sentimentos e as fantasias quanto à doação, esclarecer quanto ao processo cirúrgico e recuperação e preparálo para uma possível rejeição do rim por parte do receptor.

A primeira entrevista psicológica com o receptor tem por objetivo conhecer a motivação do paciente e suas expectativas relacionadas ao transplante, auxiliando-o a clarificar as fantasias relativas ao transplante e a sua deficiência renal. Analisa também suas emoções e a percepção que tem de si após o diagnóstico da deficiência; examina, ainda, os esclarecimentos procedidos, tanto pelo médico como pela enfermeira, relativos ao processo cirúrgico e cuidado pós-transplante, checando, a partir do seu discurso e suas manifestações emocionais, se as informações e orientações foram efetivamente compreendidas. O objetivo é possibilitar a diminuição da ansiedade diante do processo cirúrgico, mas o que acontece, muitas vezes, é a manifestação de sentimentos e fantasias latentes relativos à rejeição da deficiência renal e ao tratamento de hemodiálise. É a primeira oportunidade que o paciente está tendo para entrar em contato com a carga de sofrimento diante de todo o seu tratamento. Faz-se mister oferecer a possibilidade de confronto do paciente com sua angústia e seu sofrimento diante de sua deficiência, buscando superála, para que ele possa integrar as fantasias atribuídas ao transplante renal com a realidade do tratamento.

O psicólogo hospitalar, junto ao paciente crônico, procurará compreender o indivíduo na sua dinâmica existencial, pois, segundo Santos e Sebastiani (1996), ser portador de doença crônica ocasiona problemas, angústia em nível existencial, tanto para o paciente como para seus componentes familiares. Dependendo dos procedimentos e contatos com a equipe multiprofissional, é modificada toda uma estrutura de vida pessoal e familiar. A atuação do psicólogo, no HUWC, visa a aprofundar o significado da experiência do paciente renal, possibilitar apreender suas vivências, facilitar a elaboração do seu momento atual.

Na entrevista psicológica com a família, é observado se há alguma alteração na sua dinâmica frente à deficiência do paciente, pois isso pode ser fator de apoio ou de dificuldade na reabilitação deste. No estudo de caso a seguir, foi observado que a comunidade se mobilizou emocionalmente e que isso repercutiu nos conflitos do paciente diante da doação.

Segundo Angerami (1996), quando a família tem ganhos secundários com a patologia, poderá querer manter o status quo da doença, dificultando a reabilitação do paciente. Outra possibilidade é se estruturar de forma que apóie o paciente na sua reabilitação. A ocorrência de uma ou de outra situação vai depender da forma como a família se estruturou em suas relações. A atitude que o paciente tem diante da doença e dos que o rodeiam também influencia. Fongaro \& Angerami (1996) citam dois tipos de tendências nas quais o indivíduo se posiciona em relação à valoração da própria vida: postura de necrofilia (morte) ou biofilia (vida), que dificultam ou potencializam a recuperação quando associadas à estrutura egóica.

A entrevista psicológica com a família (mãe e a irmã) tem como objetivos: investigar as mudanças ocorridas no cotidiano após o problema renal, tomar conhecimento das reações da família ante o problema renal e o transplante, saber quais restrições o paciente sofreu com o problema renal e quais as vantagens (se houver) em tê-las; saber se existe conhecimento e fantasias a respeito do processo cirúrgico e cuidados pós-operatórios; observar o interesse da família na realização do transplante.

A intervenção psicológica na enfermaria, de uma forma geral, ocorre diante de solicitação médica ou por necessidade observada pelo próprio psicólogo. Os focos das intervenções 
são bastante diferenciados, pois, nesse local, estão os pacientes em recuperação pós-cirúrgica, os pós - transplantados que apresentam alguma intercorrência e os que ainda não realizaram o transplante, mas necessitam de algum cuidado médico.

Com os pacientes pós-cirúrgicos, a intervenção psicológica tem objetivos diferentes, de acordo com o foco. Se este for a alta hospitalar, é dado apoio para a reabilitação do paciente e retorno ao ambiente familiar, possibilitando o afloramento de conteúdos emocionais, com o objetivo de reduzir a ansiedade gerada diante de possíveis perdas; no caso do foco na doença deficiência renal, deve-se clarificar alguma fantasia relacionada à deficiência e recuperação, auxiliar na desvinculação da hemodiálise praticada regularmente antes do transplante, estimulando a continuidade do tratamento; se houver óbito, é favorecido o apoio à família diante da perda do ente querido e o apoio à equipe de saúde diante desse momento.

Quando o foco está em torno da internação, o psicólogo estuda a implicação emocional, na família, decorrente da hospitalização do paciente, esclarecendo sobre a sua situação , suas possibilidades e limitações.

As intervenções com a família, focalizando a alta parcial, acontecem com a investigação de medos, fantasias, concepções errôneas da deficiência, relação de dependência e sofrimento que envolvem o doente e a família, com esclarecimento sobre as condições necessárias para o restabelecimento físico e emocional do paciente.

Com os pacientes pré e pós-transplantados que estão na enfermaria, a intervenção direciona-se para os pontos de urgência, que são as repercussões emocionais no processo de transplante (especialmente se paciente pré-transplante), investigando a mobilização emocional para recuperação e incentivo ao paciente.
As intervenções com a equipe multiprofissional têm como objetivo a discussão de casos de acordo com a necessidade da equipe, discussão de atitudes na relação médico-paciente se o foco for a doença. Independentemente do foco - alta, óbito - internação, a atuação se dá na facilitação do vínculo médico-família, para esclarecimento à família acerca de procedimentos relacionados ao paciente.

\section{Estudo de caso}

\section{Dados de identificação}

L.A.S, do sexo feminino, procedente de Mossoró/RN, é o 5a rebento de uma prole de oito (idades: 30 , 29, 28, 24, 22, 21, 20, 18 anos). Nasceu em 23.08.78. Fez transplante com doador vivo, o irmão, dois anos mais novo.

\section{Metodologia}

O foco para esse estudo de caso foi o processo emocional pelo qual passou o paciente renal crônico diante do transplante: ela, o doador e a família.

Para descrição do caso, são utilizados nomes fictícios para o doador, o receptor e seus familiares, respeitando o anonimato: Maria é a receptora, José é o doador, a mãe de Maria é Clara, e sua irmã é Júlia.

O acompanhamento psicológico foi iniciado no ambulatório de pré-transplante, ou seja, antes da cirurgia, e continuado na enfermaria, após o transplante.

\section{Os atendimentos ocorreram da seguinte forma:}

individual - realizado no início do processo, com Maria (receptora) e José (doador), para investigar melhor os conflitos como também para a elaboração das emoções e expectativas mútuas diante do processo da doação/ recepção;

em dupla com José e Maria - quando ficou 
explícito o conflito entre eles, momento em que foi focalizada para Maria e José a importância de serem expostas suas dúvidas, angústias, expectativas e fantasias, um diante do outro, relativas à doação e ao póstransplante;

- a família (mãe e irmã) - no dia anterior ao transplante, com esclarecimentos e facilitando a elaboração das fantasias relativas ao processo do transplante e às limitações e autonomia do paciente renal crônico.

\section{Descrição e análise do caso}

No estudo de caso descrito adiante, as intervenções com a paciente na enfermaria focalizaram a continuidade do tratamento. A alta foi focada tanto com a paciente como com a família, representada pela mãe e a irmã.

O atendimento à família já era uma demanda da paciente surgida durante o seu acompanhamento pré-transplante, pois esta percebia o quanto a mãe se culpava diante da sua deficiência renal, sendo que esse fato dificultava a relação entre ambas.

Os atendimentos descritos serão o $1^{\circ}, 4^{\circ}, 6^{\circ}, 7^{\circ}, 10^{\circ}, 11^{\circ}, 14^{\circ}, 15^{\circ}$. Em sua maioria, foram realizados com o receptor e doador, com exceção do $4^{\circ}$ atendimento, efetivado somente com José, e o $10^{\circ}$ atendimento, desenvolvido com Clara (mãe) e Júlia (irmã).

Os atendimentos psicológicos (até o $10^{\circ}$ atendimento) ocorreram no ambulatório de prétransplante, no mesmo horário do atendimento médico e das orientações de enfermagem. $\mathrm{O}$ $11^{\circ}$ atendimento aconteceu na enfermaria, após o transplante. $\mathrm{O} 14^{\circ}$ e o $15^{\circ}$ foram realizados no ambulatório pós-transplante.

A periodicidade dos atendimentos psicológicos foi variada. No início, ocorreu um atendimento por mês, coincidindo com os retornos à consulta médica, aumentando para um atendimento semanal quando despontou a crise relacional com o doador e até o momento do transplante.
Segundo Chiattone, 2000, a atuação do psicólogo hospitalar está diretamente determinada por limites institucionais, pela instituição em si - o hospital -, caracterizada por regras, rotinas, condutas específicas, dinâmicas que devem ser respeitadas e seguidas, limitando as possibilidades de atuação do profissional.

A seguir, é relatado o processo emocional dos envolvidos - doador, receptor, família, representada pela mãe e irmã - no processo de doação.

\section{Processo emocional de Maria, de José, de Clara e Júlia}

Primeiro atendimento psicológico: Maria, que saíra há pouco tempo da consulta com o médico e havia recebido as orientações da enfermeira, apresentou-se com fantasias de cura diante do transplante renal e forte rejeição à hemodiálise. Foram feitos esclarecimentos sobre as limitações e possibilidades do transplante, com o objetivo de auxiliar Maria a elaborar suas fantasias.

Segundo Chiattone, no hospital, a capacidade de antecipação do psicólogo hospitalar ao paciente reflete a coerência dessa prática, dentro de uma lógica pautada pela prevenção do sofrimento psíquico. Além disso, segundo as normas fundamentais da prevenção, quanto mais precoce for a intervenção, menores as possibilidades de agravamento e maiores as expectativas de recuperação psíquica dos pacientes.(...) A intervenção é norteada pela terapia breve e/ou de emergência, de apoio e suporte ao paciente, considerando-se o momento de crise vivenciada pelo indivíduo na situação especial e crítica de doença e hospitalização.

No caso, foi expressa a disponibilidade do acompanhamento psicológico e ela o aceitou. Logo em seguida, foi realizada a entrevista com José, que se apresentou otimista e decidido na sua posição de doador.
A intervenção é norteada pela terapia breve e/ou de emergência, de apoio e suporte ao paciente, considerando-se o momento de crise vivenciada pelo indivíduo na situação especial e crítica de doença e hospitalização. 
Quarto atendimento psicológico: José, que se apresentou tranqüilo no início dos atendimentos individuais, decidido diante da doação, com total apoio e incentivo da família e da comunidade para tal, dando apoio psicológico à irmã, começou a indicar sinais de conflitos com ela. Esses conflitos haviam sido sinalizados pela irmã em seus atendimentos individuais. Disse que a razão é a rejeição que a irmã tem por ele desde criança. Acha-a "mal-agradecida", orgulhosa e prepotente por não aceitar o seu rim. Não aceitar seu rim é rejeitá-lo como irmão.

Sexto atendimento psicológico: Maria se apresentou confusa e em dúvida quanto ao transplante. Não sabe se o fato de ter conhecido uma budista - que disse que sua deficiência era um castigo por seus pecados nessa ou em vida anterior - levou-a a ter a fantasia de ter provocado a deficiência renal e a sentir-se culpada: um aviso para não fazer a cirurgia. Foi-lhe esclarecido quanto à origem e ao processo da deficiência renal crônica, auxiliada pela nefrologista que se encontrava no ambulatório.

Maria disse que, durante a semana, fica confusa com o que ouviu e se organiza durante o atendimento. "Quando estou mal, não consigo ver as coisas boas que digo ter e que você confirma. Fico dizendo a mim mesma que estou mentindo e me enganando, como cheguei hoje aqui. E, depois, que fico menos confusa, aí essa idéia passa e me vejo mais capaz, menos ruim, mais madura".

Sétimo atendimento psicológico - com José e Maria: Maria chegou confusa diante de várias situações que a perturbavam. Expressou que estava com medo de se abrir para a psicóloga, com receio de que suas afirmações fossem entendidas pela profissional como uma negativa do transplante. Os conflitos cotidianos com José estão exacerbados, levando a paciente a apresentar dúvidas quanto ao transplante com doador vivo. Está com medo de perder sua autonomia, de se submeter às vontades de José, de ser controlada por ele, ficar em dívida eterna com o irmão pelo fato de ter recebido seu rim. José sempre foi agressivo com ela e acha que ele vai querer controlá-la pelo fato de doar o rim, e não quer isso para a vida dela. Está recebendo pressão familiar como de toda a sua cidade, para aceitar o rim do irmão; sua vida está pública, e todos exigem que seja grata pela atitude do irmão. Está chateada com essa cobrança. Está pensando que o irmão quer doar porque a mãe não tem condições de mantêla em Fortaleza fazendo hemodiálise. Tem medo de decepcionar a família se não aceitar a doação. Repete que Clara se sente culpada por Maria ter adoecido aos 12 anos. Maria está pensando em continuar na hemodiálise e esperar um rim-cadáver, mas tem medo quanto ao percentual de rejeição, caso receba um rim-cadáver. Sente-se desamparada e desencorajada a conversar com José sobre sua decisão.

A intervenção estimulou ambos ao confronto de suas expectativas e à clareza das emoções diante dos conflitos em virtude da doação/ recepção do rim, haja vista que José também já havia manifestado seus sentimentos em sessão individual anterior. Após escutar José novamente, em separado, o momento seguinte foi o do atendimento com ambos, pois José também demonstrou a necessidade de se abrir com Maria. Foi possibilitado o confronto entre os dois diante de suas defesas, valorizando as funções egóicas individuais; criou-se um apoio mais adequado para lidar com o momento. $\mathrm{O}$ resultado foi considerado positivo.

Watzlawick (1999) enfatiza que toda relação é comunicação. É impossível não comunicar. Os membros da família se interligam, se relacionam, influenciam e são influenciados através das relações que mantêm entre si.

Décimo atendimento psicológico - com a família - Clara e Júlia estavam presentes para acompanhar a internação pós-transplante. A paciente e o irmão haviam adiantado a 
dificuldade da mãe em aceitar a deficiência renal.

Segundo Campos (1995), quando a doença se instala no indivíduo, muitas vezes, em conseqüência, surge um desajustamento do grupo familiar, tornando-se necessário o apoio psicológico aos membros da família.(...) O psicólogo ajudará a família, conscientizando-a da real situação do doente e da necessidade de tratamento e hospitalização. Os vários aspectos devem ser aclarados para os familiares, pois estes precisam sentir-se apoiados e seguros, com suas dúvidas esclarecidas.

No atendimento com Clara e Júlia, conversouse sobre a deficiência renal e a alteração que causa no cotidiano, cientificando-se a mãe quanto aos limites e à autonomia de sua filha. A mãe, que, no início do atendimento, se recusava a falar de suas emoções frente à deficiência renal da filha, conseguiu refletir sobre as expectativas e planos inconscientes que alimentara, razão dos conflitos entre ambas, os quais já haviam sido referidos por Maria em seus atendimentos.

Décimo primeiro atendimento - (primeiro atendimento pós-cirúrgico, na enfermaria): Maria está tranqüila e cheia de planos. Agradece a presença da psicóloga e as orientações recebidas.

Décimo quarto atendimento - primeiro atendimento no ambulatório pós-transplante: Maria expressa sua confusão diante da dinâmica familiar, alterada para melhor. Seu pai, que nunca demonstrou afeto, está mais atencioso, mais carinhoso com todos os filhos e os netos. "É só festa na minha casa". Termina seu discurso com uma pergunta: "Precisava eu ficar doente para acontecer tanta coisa boa? E por que eu fui a escolhida para ficar doente? Por que passar por tanta dor e sofrimento para mudarem?"

Sente que a mãe quer superprotegê-la, por isso não quer voltar para Mossoró,RN. Essa atitude materna Ihe passa a sensação de inutilidade. Sente que as pessoas de sua cidade Ihe cobram um reconhecimento pelo apoio que deram através de orações e esperança. Essa cobrança lhe dá a sensação de estar sendo ingrata para com todos.

Além do medo de perder o rim, tem vários outros: de não conseguir retomar sua vida, principalmente retornando para casa, onde a família inteira vai " sufocá-la", superprotegê-la. Está feliz por ter a possibilidade de uma nova vida e triste pelo esforço necessário para mantêla. Percebe, agora, que os conflitos entre ela e o irmão são normais. Está aprendendo a expressar seus sentimentos para com todos.

Décimo quinto atendimento - o último atendimento com Maria foi uma reflexão sobre o passado, o presente e o futuro, suas diferenças no cotidiano; a fase de luto que passava pelos planos que fizera para sua vida e precisavam ser readaptados; esclarecimento do processo emocional e incentivo a decodificar as emoções: o fato de negá-las ou reprimi-las não tira sua existência. É necessário "escutá-las" para obter os benefícios de sua mensagem. Elas nos levam a refletir sobre perdas, ganhos e conduzem a pensar sobre as opções possíveis.

Torna-se mister ressaltar que, segundo Chiatonne, 2000, a situação de crise caracterizase como um momento de instabilidade psíquica que pode resultar em amadurecimento, crescimento psicológico, pelas oportunidades vivenciadas pelo paciente na busca de soluções, como também um momento gerador de soluções mal adaptativas e que o colocam em um nível inferior de funcionamento, com o aparecimento dos sintomas. Maria agradeceu o apoio que teve durante o seu processo e diz ter tirado muito proveito, inclusive sua família. Para todos, foi um aprendizado.

\section{Considerações finais}

Pode-se considerar que, nesse acompanhamento psicológico, o processo de receber e de doar
Além do medo de perder o rim, tem vários outros: de não conseguir retomar sua vida, principalmente retornando para casa, onde a família inteira vai " sufocá-la", superprotegê-la. 
passou pela dinâmica individual do doador, do receptor e da família, ativando conflitos até então inconscientes, mas que influenciavam na decisão e no equilíbrio emocional do paciente, que queria submeterse ao transplante. Ainda foram ativados conflitos naqueles que, de forma direta, estavam envolvidos com o decurso da cirurgia e seu período anterior e posterior.

Fazendo um caminho do processo emocional de Maria, pode-se observar o alívio da pressão emocional interna, abertura para o diálogo franco e esclarecedor das suas emoções com seu irmão, gerando espaço para confiança mútua e cumplicidade. Isso permitiu uma decisão mais madura pela recepção do rim do irmão, culminando com o sentimento de esperança no sucesso do transplante. Possibilitou também, ao doador, alívio dos conflitos internos da relação fraternal da infância e adolescência, levando-o a uma opção consciente da doação. O doador foi capaz de reconhecer a influência psicológica que a família e a comunidade exerciam sobre ele.

O espaço psicológico criado para responder à demanda de preparação para o transplante evolui para um processo existencial, no qual afloram conflitos intra e inter-relacionais. Com a elaboração desses conflitos, o objetivo inicial, o transplante, transcende para o autoconhecimento. A deficiência renal pode significar, portanto, uma ponte para o enfrentamento da própria vida ao lidar com fragilidades e medos. Também possibilita descobrir fortalezas, coragem e perseverança, notando que é ele, paciente, o grande condutor da sua história.

A utilização da técnica de psicoterapia breve de apoio e o conhecimento da dinâmica da instituição hospitalar foram determinantes na condução do processo, possibilitando a prática interdisciplinar e a realização de intervenções que resultaram em redução de sofrimento psíquico na paciente. Houve o enfrentamento das limitações impostas pela deficiência e a descoberta de opções para conviver com ela. O apoio, através do espaço psicológico acolhedor e seguro, permitiu à paciente perceber que ela tem uma deficiência renal e que sua história existencial não se limita a ela. A elaboração de fantasias, as informações sobre a deficiência renal, sobre o transplante, viabilizados pelas intervenções da PBA, possibilitaram um descobrir-se emocionalmente em suas várias relações.

Essa experiência como extensionista trouxe uma percepção clara da fronteira que diferencia a atuação do psicólogo clínico e a do psicólogo hospitalar. A abordagem teórica do psicólogo clínico, que o auxilia na interpretação da dinâmica do paciente e nas suas intervenções, se torna insuficiente para o contexto hospitalar. É necessário o acréscimo de informações sobre a dinâmica da própria instituição hospitalar, pois esta, através de suas normas, define, de forma direta, os settings terapêuticos nos quais se dá a atuação do psicólogo. O profissional precisa, então, ser flexível e ter recursos técnicos (como a PBA) para desenvolver seu trabalho. A supervisão com a psicóloga, também hospitalar, se fez necessária para iluminar a cultura da instituição, clarear possíveis obstruções nos canais de comunicação entre os membros da equipe, entre a equipe e o paciente e entre o paciente e sua família, além de possibilitar ao psicólogo perceber possíveis fatores que podem sobrecarregá-lo psiquicamente e impedi-lo de realizar uma atuação eficaz.

O projeto de extensão em capacitação hospitalar no serviço de transplante renal do HUWC foi avaliado como satisfatório e resultou na criação de uma vaga para psicólogo concursado nesse serviço. Isso demonstra a seriedade do trabalho desenvolvido e o respeito pela pessoa portadora de deficiência renal, que traz um sofrimento psíquico sobreposto ao sofrimento físico. Além disso, demonstra que o psicólogo tem instrumentos teóricos e práticos para desenvolver assistência no âmbito hospitalar. 
Maria Lúcia Pinheiro Garcia psicóloga clínica, Mestre em Saúde Pública - UECE Rua Pedro Firmeza, 1422 - Cambeba - Fortaleza/CE

CEP: 60822-380.

E-mail: branca@secrel.com.br

Ângela Maria Alves e Souza Enfermeira. Doutora em Enfermagem. Docente do Curso de Graduação e Pós-graduação em Enfermagem da UFC. Rua João Sorongo, 1891-Rodolfo Teófilo - Fortaleza/CE CEP: 60430-440 E-mail: amas@ufc.br

Teresa Cristina Holanda

Psicóloga do Departamento Materno-Infantil do Hospital Universitário Walter Cantídio, da Universidade Federal do Ceará UFC. Mestra em Saúde Pública. Professora do curso de Psicologia da Universidade de Fortaleza

Rua Rafael Tobias, 2801 - Casa 20 - Edson Queiroz - Fortaleza/CE CEP: 60833-680 E-mail: teresa@unifor.br

ANGERAMI. V.C A Ética na Saúde. São Paulo/SP: Pioneira,1997.

CAMPOS, T C P. Psicologia Hospitalar: a Atuação dos Psicólogos em Hospitais. São Paulo: EPU, 1995

CAPLAN, G. Principles of Preventive Psychiatry. New York: Basic Books, Inc., 1964

CHIATONNE, H B C. A Significação da Psicologia no Contexto Hospitalar. In Psicologia da Saúde: um Novo Significado para a Prática Clínica. São Paulo/SP : Pioneira, 2000.

CORDIOLI, A. V. As Psicoterapias mais Comuns e suas Indicações. In Psicoterapias: Abordagens Atuais. Porto Alegre/RS : Artes Médicas Compacta, 2ed.,1993.

FONGARO, M.L.H e SEBASTIANI,R.W. Roteiro de Avaliação Psicológica Aplicada ao Hospital Geral. In Camon, V.A.(org.) E a Psicologia Entrou no Hospital. São Paulo : Pioneira, 1996.

GOUVÊA, A. H. Psicoterapia Breve de Apoio. In Lemgruber, V. O Futuro da Integração - Desenvolvimentos em Psicoterapia Breve. Porto Alegre/RS : ArtMed, 2000.
LEMGRUBER, V. Psicoterapia Breve Integrada. Porto Alegre/ RS:Artes Médicas Sul Ltda, 1997.

MINUCHIN, Salvador. Famílias: Funcionamento \& Tratamento. Porto Alegre:Artes Médicas, 1990.

PAPP, Peggy. O Processo de Mudança: uma Abordagem Prática à Terapia Sistêmica de Família Porto Alegre/RS:Artes Médicas,1992.

SANTOS, C. T. e SEBASTIANI, R. W. Acompanhamento Psicológico à Pessoa Portadora de Doença Crônica. In. Camon, V.A.(org.) E a Psicologia Entrou no Hospital. São Paulo/SP: Pioneira, 1996, pp.147-175.

SATIR, Virgínia. Terapia do Grupo Familiar. Rio de Janeiro/RJ : F. Alves, 5 ed., 1993.

URYN, M.B. Transplantes Renais. In Filho, Júlio de Mello. Psicossomática Hoje. Porto Alegre/RS: Artes Médicas, 1992.

WATZLAWICK, Paul; BEAVIN e JACKSON, Don D. Pragmática da Comunicação Humana. 12 ed. São Paulo: Cultrix, 1999. 